\title{
INTERCULTURALIDAD Y CONVIVENCIA ESCOLAR: UNA NUEVA ETAPA PARA LA COMUNIDAD ESCOLAR CHILENA
}

\author{
INTERCULTURALITY AND SCHOOL CLIMATE: \\ A NEW STAGE FOR THE CHILEAN SCHOOL \\ COMMUNITY
}

MARÍA JOSÉ CARES GEOFFROY*

Rec.: 17-11-2019 Acept.: 18-06-2020 Publ.: 30-jun-2020

DOI: http://doi.org/10.29035/ucmaule.58.35

\section{RESUMEN}

El objetivo de esta investigación es revelar la atingencia de la gestión de convivencia escolar a la interculturalidad existente en establecimientos municipales chilenos y en segundo lugar, conocer la realidad escolar de 25 familias extranjeras escogidas debido al fenómeno masivo de niños inmigrantes en las ciudades de Los Ángeles y Mulchén. La metodología utilizada es de tipo cualitativa y se utiliza como técnica de relevamiento de información el análisis cualitativo de contenido (Mayring, 2000). Para analizar los planes de gestión de convivencia escolar y para conocer la realidad de los inmigrantes en escuelas chilenas, se realiza la entrevista en profundidad a 25 familias. En los resultados observamos que los manuales de gestión de la convivencia no revelan un registro del trabajo de la interculturalidad, a la vez, no se socializan con la comunidad escolar y evidentemente esto conlleva a que algunas familias reciban tratos discriminatorios por parte de los estudiantes chilenos.

Palabras clave: interculturalidad, convivencia escolar, familias, establecimientos municipales.

\section{ABSTRACT}

The objective of this research is to reveal the relevance of the management of school climate to the interculturality existing in Chilean state schools and, secondly, to know the school reality of 25 foreign families chosen due to the massive phenomenon of immigrant children in the cities of Los Angeles and Mulchén. The methodology used is of a qualitative type and the qualitative content analysis (Mayring, 2000) is used as an

* Universidad del Biobío, Chile. mcares@lavd.cl 
information survey technique to analyze school coexistence management plans and to know the reality of immigrants in Chilean schools, the In-depth interview with 25 families is used. In the results, we observe that the climate management manuals do not reveal a record of the work of interculturality, at the same time, they are not socialized and leads to some children receiving discriminatory treatment from Chilean students.

Key words: Interculturality, School Climate management plan, families, Chilean context, state schools.

\section{Introducción}

Las sociedades actuales se caracterizan por sus movimientos migratorios y es un fenómeno masivo en América Latina. Estudios en Chile han abordado este tema desde diferentes enfoques disciplinarios, entre estos el histórico y demográfico (Cano \& Soffia, 2009). Sin embargo, desde el ámbito educativo es algo que no está saturado, siendo la principal corriente que mueve civilizaciones. Hoy imaginamos ser sujetos no sólo desde la cultura en que nacimos, sino desde una enorme variedad de repertorios simbólicos y modelos de comportamiento (García, 2004). Es por esto que se debe esclarecer la diferencia entre multicultura e intercultura. Como explica Jansen (2004), el primero, se articula a las concepciones de comunidades y ciudadanía, siendo un elemento más de diversidad cultural junto con los rasgos y características culturales de los sujetos, mientras que el segundo explica la idea de relaciones entre culturas y la capacidad de asumir el respeto mutuo, la participación y el auto reconocimiento (Mato, 2009), es decir, se expresa en toda su forma cuando existe una sana convivencia en un contexto de diversidad cultural.

\section{Justificación}

En Chile, la cantidad de inmigrantes ha ido en aumento desde hace tres años y el fenómeno ha causado impacto en el ámbito social y educativo, entre otros. Según la encuesta CASEN, hacia el año 2015 la población inmigrante predominante pertenecía a peruanos, colombianos y argentinos. Sin embargo, el Instituto Nacional de Estadísticas dio a conocer los resultados del Censo 2017 en cuanto al país de nacimiento de los migrantes y se determinó que luego de las mencionadas, le siguen la venezolana con un 11,2\%, y la haitiana en menor porcentaje. 
La Leysobre Violencia Escolar20.536 (2011) refuerza la Política de Convivencia Escolar (2009) mediante la cual se exige a todos los establecimientos tener un comité de convivencia escolar, un plan de gestión y acción de esta, un reglamento de convivencia escolar junto con los protocolos de actuación y finalmente, un encargado de convivencia escolar. El Ministerio de Educación lo despliega al sistema proponiendo el derecho a la educación y la libertad de enseñanza, inspirándose en principios que acercan a todos a recibir una educación de calidad. Desde esta posición, todos los establecimientos deben contar con reglamentos internos que establezcan la normativa y acciones dentro de planes de gestión y acción de la convivencia escolar. Sin embargo, no existen estudios que favorezcan al conocimiento de estas prácticas y a la atingencia de estas con la interculturalidad.

La UNESCO $(2008,2013)$ define a la escuela como un lugar que debiese ser un espacio en donde los niños construyen aprendizajes académicos y socioemocionales y aprendan a convivir de manera democrática, convirtiéndose en protagonistas de sociedades más justas. Por esta razón, en Chile durante la última década, la gestión de la convivencia escolar se ha transformado en un tema prioritario en el plano de las políticas educacionales (Nail, et al., 2018), y debiera considerar a toda la comunidad educativa, incluyendo a familias extranjeras que llegan a establecimientos y deben ajustarse a la normativa establecida. Por esto es necesario revelar la situación de familias migrantes en las escuelas municipales chilenas en cuanto a las actualizaciones realizadas por los establecimientos de acuerdo a los planes de Gestión de Convivencia Escolar al contexto diversificado de estudiantes migrantes, ya que la educación intercultural convence a los actores de las comunidades educativas a la vida democrática, participación e inclusión de familias provenientes de otros territorios ya sea interregionales e internacionales.

\section{Adaptación e Integración}

La experiencia de la migración forzada para un niño y/o adolescente es compleja cuando se habla de etapa de desarrollo psicosocial (infancia-adolescencia), de socialización (amistades y lazos), de idioma, religión y una nueva vivencia escolar lejos de su país (Avaria, 2012). Dentro de esto, se manifiestan dos procesos fundamentales de familias migrantes que las autoras BarriosValenzuela \& Palou-Julián (2014) destacan, uno es el proceso de adaptación que depende de ellos y el proceso de integración que depende principalmente de los otros. Debido a esto, es importante conocer el contexto de los 
migrantes y de los chilenos que forman una nueva realidad en los establecimientos. De esta manera, Jordan (1996) propone estrategias eficaces para fomentar la educación intercultural, entre las cuales dice que ya no se debe pretender a una multiplicación de actividades curriculares sino a la consecución de unas cuantas aptitudes básicas para funcionar adecuadamente en nuestras sociedades multiculturales por parte de la comunidad escolar. De este modo, trabajar el trato hacia las minorías desde la propia perspectiva de la realidad, en donde el ejecutor sea el profesor, que debe mediar, prepararse para enfrentar la educación intercultural y saber traspasarla a los estudiantes será de gran relevancia. Cabe mencionar que la influencia de la personalidad del maestro, sus valores y creencias, transmitan un cambio positivo de actitudes en torno a la diversidad cultural.

De este modo es necesario conocer que Chile es un país con una diversidad cultural latinoamericana mayor en donde los receptores deben adaptarse a los cambios, a las constantes migraciones y deben estar preparados para convivir en un ambiente de respeto como dice la normativa vigente, para así, en los establecimientos educacionales y desde la educación formal e informal, transmitir desde pequeños la empatía.

\section{Chile y el proceso migratorio}

Resulta relevante conocer hacia dónde ha avanzado Chile en temas migratorios y principalmente cómo lo están abordando los establecimientos educacionales con la llegada masiva de más de 21 mil niños migrantes que estudian en colegios públicos. Según datos proporcionados por el Ministerio de Educación, en los establecimientos subvencionados no llega a los 10 mil y en los particulares bordea los mil, entre venezolanos, peruanos, colombianos, entre otros. El interés que está ganando la educación multicultural en Chile es observable por los planes que ha enviado el Ministerio de Educación y responde a la sensibilidad de criterios, al abordaje de la interculturalidad en las salas de clase y a la preparación de las comunidades educativas al recibimiento y a la convivencia entre culturas. Avaria (2012) habla sobre el impacto del proceso migratorio para la persona que lo experimenta y que se debe tener en cuenta cuando se investiga a personas que han cruzado fronteras, estos son, la corporalidad y el rol del sujeto. El primero, ya que las experiencias migratorias son experimentadas desde allí y el segundo porque son ellos en tiempo y espacio que viven estas experiencias desde procesos internos y externos. 


\section{Inmigrantes, políticas públicas y educación}

A la hora de concebir la migración, aparecen las etiquetas que los contextos han asimilado y superpuesto a modo de referencia. Aguilar (2012) argumenta que las políticas públicas son uno de los instrumentos de rotulación, etiquetado y construcción de significado social de esta categoría que junto con los diversos contextos y los medios de comunicación nos permiten cualificar sin conocer más allá la realidad. Por esta razón, la acción social debe tener como base los valores y políticas como un modelo a seguir, en donde los agentes socializadores, la familia y la escuela deben estar ajustados a transmitir un mensaje valórico en cuanto a lo que está viviendo la sociedad actual. Por ejemplo, diversos estudios en Latinoamérica tratan la capacidad de los Estados para implementar políticas públicas que resguarden el derecho de los grupos en general, ya sean ciudadanos o ciudadanos migrantes. En Colombia, el Estado para tratar desigualdades históricamente acumuladas, garantizar la igualdad de oportunidades, o compensar costos provocados por la discriminación de determinados grupos por motivos étnicos, religiosos, sexuales o de género, ha implementado medidas de carácter temporal (Cruz, 2015). En Ecuador, la "Ley Reformatoria", que reconocía el derecho indígena dentro de la educación, releva al sistema educativo asumir la perspectiva intercultural como un criterio extendido a toda la nación y al conjunto de las relaciones sociales de convivencia (Puente, 2005). En Chile, instituciones de servicio pusieron en marcha el proyecto de ayuda al migrante, en donde se necesitaron nuevas herramientas que ya no era sólo de entrega de alimentos, sino un horizonte más amplio en donde se exigió una profesionalización (Cano \& Ávalos, 2012). De esta manera los Estados y personas van adquiriendo un sentido de equidad y la educación, mediante la formación valórica es la base de todos los comportamientos.

\section{Convivencia Escolar}

La Ley General de Educación 20.370 y la temática de Convivencia Escolar (2009), se refieren al flujo migratorio desde hace algunos años, en donde el entramado principal debe nacer desde el respeto y la valoración de la diversidad cultural, para convivir de manera tolerante y solidaria. Es muy importante que todos los establecimientos remarquen esto, ya que siendo estos un agente socializador, deben presentar un discurso positivo mediante un reglamento interno de convivencia escolar actualizado que se enmarque en la normativa y que lo ofrezca a toda la comunidad escolar. Por esta razón, las aulas constituyen un entorno de desarrollo personal y social en donde los ni- 
ños, jóvenes y adultos han de convivir (Ramírez \& Justicia, 2006). El Ministerio de Educación promulgó la Ley sobre Violencia Escolar (2011) para poder implementar líneas de acción que fortalezcan las relaciones entre los miembros de toda la comunidad educativa, para así desarrollar un ambiente de respeto de todo el centro escolar. Sin embargo, se puede producir un distanciamiento entre la teoría y la práctica, limitando el impacto real de los manuales de convivencia escolar, pues su aplicación varía dependiendo del conocimiento o ignorancia de estos, no cumpliendo enteramente su objetivo y sumado a esto, la falta de empoderamiento del instrumento por la comunidad educativa (Nail et al., 2018). Debido a esto, es muy importante socializar los planes de convivencia y que garanticen los lineamientos internos del propio establecimiento, ya que cada escuela debe responder a su comunidad educativa. Con la Ley sobre Violencia Escolar 20.536 (2011) se refuerza la Política de Convivencia Escolar mediante la cual se exige a todos los establecimientos tener un comité de convivencia escolar, un plan de gestión y acción de esta, un reglamento de convivencia escolar junto con los protocolos de actuación y finalmente, un encargado de convivencia escolar para así trabajar la prevención, la mediación y la solución dentro de cada establecimiento.

\section{Interculturalidad, Convivencia Social y Escolar}

La investigación acerca de familias migrantes realizada por Garreta (2000) analiza la trayectoria que ha seguido España en materia de inmigración, los procesos de los emigrantes-inmigrantes, también las características de los flujos actuales, los procesos legales y políticos por la cuestión migratoria y las consecuencias que ha traído, principalmente en el ámbito educativo y social. Por consiguiente, en Europa, estos procesos se han vivido con al menos veinte años de anticipación a lo que es América Latina, y en Chile, son vivencialmente casi nuevos para la sociedad en cuanto a lo masivo del fenómeno y lo mismo sucede al hablar de Convivencia escolar, del cual se abordarán los sustentos más adelante.

La interculturalidad se define como la relación entre culturas y actualmente, como describe García (2004) los Estados y las legislaciones nacionales, las políticas educativas y de comunicación que ordenaban la coexistencia de grupos en territorios acotados son insuficientes ante la expansión de mezclas culturales, por este motivo, se hace más complejo avanzar en países tercermundistas. Para esto, es necesario transparentar los conceptos de multicultura e intercultura y así seguir avanzando, ya que, como explica este autor, desde un mundo multicultural, pasamos a otro 
intercultural globalizado que se ha centrado en mantener el concepto de intercultura desde estudios de etnias locales nativas propias de los países. Por ejemplo, en México, explica Valverde (2010), la educación pasó de ser bilingüe bicultural a bilingüe intercultural, apoyando a los pueblos indígenas y a la vez a los inmigrantes. Sin embargo, desde otra perspectiva, Clastres en Novaro (2011) revela la posición de los Estados y muestra que el Estado occidental y capitalista es el más etnocida de todos. A este efecto, los autores apuntan a que por parte del Estado emergen situaciones de marginalidad y de disparidad entre las minorías y las políticas, aumentando la desvalorización por parte de la sociedad que conlleva al etiquetado y más tarde se predispone al conflicto social.

Como explican Stefoni et al. (2016), la población migrante debe tener acceso a todos los derechos establecidos en igualdad de condiciones a la sociedad local, sin embargo, no queda claro por parte del Estado nación. Es por esta razón que el aseguramiento de las familias no solo se base en instrumentos legales, sino también en la real convicción por parte de la sociedad. Desde este párrafo se infiere que la sociedad está actuando, sin embargo, las políticas no lo están haciendo, ya que el comportamiento receptor de la ciudadanía chilena puede ser positivo como también negativo y se basa en los prejuicios y especulaciones según la teoría de etiquetado de Becker (1960). Las autoras Stefoni et al. (2016) parten de la premisa que algunas escuelas han comenzado a incluir nociones de multiculturalidad en sus proyectos educativos y es observado por ejemplo en eventos, en donde los niños migrantes pueden participar mostrando su cultura. Debido a esto, es relevante conocer lo que conlleva la convivencia escolar a través de la Ley sobre Violencia Escolar (2011), que explica que se entenderá por buena convivencia escolar, la coexistencia armónica de los miembros de la comunidad educativa, que supone una interrelación positiva entre ellos y permite el adecuado cumplimiento de los objetivos educativos en un clima que propicia el desarrollo integral de los estudiantes. También, la Ley Contra la Discriminación (2012) explica los tipos de discriminación y motivos los cuales puede sufrir cualquier estudiante de la comunidad, en particular cuando se funden en motivos tales como la raza o etnia, la nacionalidad, entre otros.

\section{Metodología}

El diseño metodológico de la investigación se sustenta en el paradigma comprensivo-interpretativo con base en un enfoque cualitativo, debido a que la construcción de una organización se sustenta en una misión que interpreta 
fielmente los deseos y valores de los actores sociales que en ella participan (Cornejo, 2007). Para revelar la atingencia existente entre los planes de gestión de convivencia escolar e interculturalidad en estos establecimientos es necesaria la comprensión como base de la investigación. Por esta razón este estudio se basa en el método fenomenológico ya que como explica Guardián-Fernández (2007), no parte del diseño de una teoría, sino del mundo conocido, del cual se hace un análisis descriptivo con base en las experiencias compartidas por los participantes. En este método el investigador trata de describir la realidad vivida por inmigrantes, siendo 25 familias con 37 niños migrantes estudiando en los establecimientos que se encuentran en la provincia del Bio Bío, Chile, en donde 1 pertenece a la comuna de Mulchén y los otros 24 a la comuna de Los Ángeles y es posible decir que la elección de sujetos se basa debido al factor inmigración como fenómeno masivo dentro del primer y segundo ciclo de enseñanza básica.

Se realizaron 25 entrevistas en profundidad a madres extranjeras provenientes de Colombia, Venezuela y Haití, nacionalidades predominantes en el país de acuerdo a la encuesta CASEN realizada en 2017 por el Ministerio de Desarrollo Social (ver Tabla 1). Además, para lograr el objetivo definido anteriormente, se plantea la necesidad de un alcance descriptivointerpretativo, basado en el análisis de 25 manuales de gestión de la convivencia escolar mediante el análisis cualitativo de contenido que se define a sí mismo dentro de este marco de trabajo como una aproximación empírica, de análisis metodológicamente controlado de textos al interior de sus contextos de comunicación, siguiendo reglas analíticas de contenido y modelos paso a paso, sin cuantificación de por medio (Mayring, 2000). Así se produce una revisión de los manuales de gestión de Convivencia Escolar de cada establecimiento que fueron entregados mediante formatos de documentos en papel y formatos online de páginas web de las escuelas. Mayring (2000) citado en Cáceres (2003) propone los pasos a seguir de esta técnica: La selección de un modelo de comunicación, luego de esto, un preanálisis para definir las unidades, luego, elaborar reglas de análisis basadas en estas unidades y códigos para finalmente, definir las categorías y producir la síntesis final.

La información fue recabada durante los meses de abril a noviembre del año 2018. Las entrevistas fueron realizadas en las dependencias de las escuelas estudiadas y su duración fluctuó entre los 40 y 70 minutos, además para obtener la información necesaria se crearon 4 ejes temáticos para la pauta de entrevista, que son: origen de la migración, familia, calidad de la 
estancia en Chile y comunidad escolar. Las entrevistas convocaron a madres que bajo el criterio de accesibilidad y cuyos hijos se encuentran cursando primer y segundo ciclo de enseñanza básica, aceptaron ser entrevistadas.

Tabla 1

Datos sujetos entrevistados y establecimientos.

\begin{tabular}{|c|c|c|c|}
\hline Apoderada/Escuela & Nacionalidad* & $\begin{array}{c}\text { Escuela Municipal } \\
\text { Ciudad }\end{array}$ & $\begin{array}{l}N^{\circ} \text { de hijos en } \\
\text { escuelas chilenas }\end{array}$ \\
\hline Madre-Escuela 1 & Venezolana $(\mathrm{E} / \mathrm{T})^{*}$ & Los Ángeles & 1 \\
\hline Madre-Escuela 2 & Venezolana $(\mathrm{N})^{*}$ & Los Ángeles & 1 \\
\hline Madre-Escuela 3 & Venezolana (N) & Los Ángeles & 1 \\
\hline Madre-Escuela 4 & Venezolana $(E / T)$ & Los Ángeles & 1 \\
\hline Madre -Escuela 5 & Venezolana (N) & Los Ángeles & 2 \\
\hline Madre-Escuela 6 & Venezolana (E/T) & Los Ángeles & 2 \\
\hline Madre-Escuela 7 & Venezolana (E/T) & Los Ángeles & 3 \\
\hline Madre-Escuela 8 & Venezolana $(\mathrm{E} / \mathrm{T})$ & Los Ángeles & 1 \\
\hline Madre-Escuela 9 & Venezolana (N) & Los Ángeles & 1 \\
\hline Madre-Escuela 10 & Venezolana (E/T) & Los Ángeles & 2 \\
\hline Madre-Escuela 11 & Venezolana $(E / T)$ & Los Ángeles & 2 \\
\hline Madre-Escuela 12 & Venezolana $(E / T)$ & Los Ángeles & 1 \\
\hline Madre-Escuela 13 & Venezolana (N) & Los Ángeles & 3 \\
\hline Madre-Escuela 14 & Haitiana (N) & Los Ángeles & 1 \\
\hline Madre -Escuela 15 & Haitiana $(E / T)$ & Los Ángeles & 1 \\
\hline Madre-Escuela 16 & Haitiana $(E / T)$ & Los Ángeles & 1 \\
\hline Madre-Escuela 17 & Haitiana $(E / T)$ & Los Ángeles & 1 \\
\hline Madre-Escuela 18 & Haitiana (E/T) & Los Ángeles & 2 \\
\hline Madre-Escuela 19 & Haitiana $(E / T)$ & Los Ángeles & 1 \\
\hline Madre-Escuela 20 & Haitiana $(E / T)$ & Los Ángeles & 1 \\
\hline Madre-Escuela 21 & Colombiana $(E / T)$ & Los Ángeles & 1 \\
\hline Madre-Escuela 22 & Colombiana $(E / T)$ & Los Ángeles & 2 \\
\hline Madre-Escuela 23 & Colombiana $(\mathrm{E} / \mathrm{T})$ & Los Ángeles & 2 \\
\hline Madre-Escuela 24 & Colombiana (E/T) & Los Ángeles & 1 \\
\hline Madre-Escuela 25 & Colombiana (E/T) & Mulchén & 2 \\
\hline
\end{tabular}

Fuente: elaboración propia de acuerdo a datos recogidos en trabajo de campo.

* La sigla (E/T) explica que la persona está en trámite de nacionalización, mientras que la sigla (N) da a conocer que la persona ya posee la nacionalidad chilena. 


\section{Resultados}

Primero se presenta el análisis de contenido de los manuales de gestión de la convivencia escolar para luego mostrar los resultados de las entrevistas a las apoderadas extranjeras. El primero se centró en el modelo por pasos del desarrollo deductivo-inductivo del análisis de contenido propuesto por Mayring (2000) que se define como un conjunto de técnicas de análisis de las comunicaciones utilizando procedimientos sistemáticos y objetivos de descripción del contenido de los mensajes (Bardin, 1996). Este se basa en 7 pasos que son, selección de un modelo de comunicación, pre-análisis, definición de unidades de análisis, elaboración de reglas de análisis, elaboración de códigos, definición de categorías y una síntesis final.

\section{a. Análisis cualitativo de contenido de planes de gestión mediante las acciones y ejecuciones del trabajo de la interculturalidad.}

Se parte desde la selección del objeto de análisis dentro de un modelo de comunicación, que en este caso es el escrito y se identifica con el plan de gestión adecuado en acciones a la interculturalidad existente. De acuerdo a esto surge avanzar al pre-análisis y hay que considerar que lo que se busca es constituir un corpus de análisis (Bardín, 1996) que según Cáceres (2003) se obtiene mediante notas de campo, entrevistas, discursos y que en este caso fue, a través conversaciones previas con los encargados de convivencia escolar y directores que explican la importancia de la interculturalidad en la escuela y cómo se trabaja, nombrando categorías que debieran estar dentro de planes de acción. Sin embargo, desde el momento en que no todos los fenómenos sociales son susceptibles de ser observados en el tiempo de su ocurrencia por transmisión oral, cobran importancia los documentos escritos por su capacidad de convertirse en registros históricos a los que se puede acudir con relativa facilidad (Fernández, 2002). En la Tabla 2 se realiza el análisis de contenido trabajado desde los 7 pasos explicados por (Mayring, 2000) y se expone aquello que nos interesa para la relación de códigos que dan lugar a categorías (Cáceres, 2003).

Como síntesis final del análisis de contenido del trabajo de la interculturalidad en los planes de gestión de convivencia escolar en los 25 establecimientos municipales, se pudo observar su contenido y separarlo en dos términos que son el "manifiesto" y "latente" (Cáceres, 2003). El primero significa que el trabajo se encuentra en las acciones del plan de gestión de la convivencia escolar (CE), mientras que el segundo significa que no 
se encuentra en las acciones del plan de gestión de la CE. Para comenzar, la diversidad cultural se manifiesta en los planes de gestión en apenas cinco establecimientos, 4, 11, 12, 14 y 25 y lo hacen mediante el trabajo de la aceptación e inclusión en las aulas, sin especificar la actividad en concreto (ver Tabla 2). En los restantes la acción de trabajo de la diversidad cultural se encuentra latente. Las jornadas interculturales se manifiestan sólo en el plan de gestión del establecimiento 4, que lo trabaja mediante stands de comidas y vestimentas típicas una vez al año, mientras que en los otros 24 establecimientos se encuentra latente. En el caso de los recursos del Ministerio, no se interpreta en ningún plan de gestión, por lo tanto en las 25 escuelas se encuentra latente. Por otro lado, el trabajo de valores se manifiesta en tres escuelas $(5,10,25)$ y lo practican mediante charlas del profesorado a niños y apoderados en jefaturas, en los otros 22 establecimientos se omite este trabajo (latente). De acuerdo a la innovación del profesorado, se encuentra manifiesto en dos planes de gestión de dos colegios $(1,5)$. Es interesante mencionar que en estos establecimientos los docentes han participado en charlas que tratan el tema migratorio en Chile y lo traspasan a sus alumnos en actividades. El plan de acogida junto a las prácticas culturales se encuentra latentes en las acciones de los planes de gestión. Es relevante agregar que los informantes previos de cada establecimiento dieron a conocer que existen actividades en las cuales se trabaja la interculturalidad, sin embargo en el plan de gestión (acciones) no están manifestadas. Es importante que se evidencien y se socialicen para promover la participación. Además es relevante conocer que desde el Ministerio de Educación existen orientaciones para el trabajo con inmigrantes en las aulas chilenas, técnicas que se deben implementar, como lo son recursos materiales y la nueva Política Nacional de Estudiantes Extranjeros (2018-2022) que ayuda a su inclusión en el sistema educacional. Fernández (2002) explica que esta técnica muestra las características internas para conocer los valores en que se basa y los principios que apoya. De esta manera, los mensajes que pretende transmitir el documento en estudio, revelaron que no existe el trabajo de la interculturalidad con la práctica de la convivencia escolar en esta temática, ya que sólo 3 establecimientos manifiestan en sus acciones al menos 2 códigos elaborados en la revisión para el análisis, que son las escuelas 4, 5 y 25. Si bien no se puede asegurar que el análisis de contenido, cualitativo o no, permita generar teoría (Valles, 2000), al menos se puede pensar en la mantención de su carácter analítico por cuanto implica una reestructuración o conformación de datos brutos hacia una nueva configuración teórica, a la manera de marcos o modelos teóricos. 


\section{b. Realidad de las familias extranjeras en establecimientos municipales}

Se percibe de manera compleja entender la realidad de otros hasta el momento de vivir las situaciones, es por esto que para estudiar la migración, es necesario observar e interactuar con inmigrantes para entender este proceso (Avaria, 2012).

En opinión de las entrevistadas, la gran mayoría de los estudiantes haitianos ha recibido tratos vejatorios en los colegios por parte de los niños y no solamente en la escuela, también en la calle.

"Le decían negro a mi hijo" (Madre haitiana de $6^{\circ}$ básico)

"El no entendía el idioma, sólo veía que se reían de él" (Madre haitiana de $5^{\circ}$ básico)

"Le decían hedionda a mi hija, que se volviera a su país... ellos no entendian lo que es salir del país y pasar por esto" (Madre haitiana de $5^{\circ}$ básico).

En el caso de las familias, ellas no saben a quién dirigirse para conversar la situación y expresan que se les ha entregado los manuales y reglamentos que poseen las escuelas, sin embargo, ellas no comprenden el idioma, además observan que estos no se socializan en ningún evento por parte de la escuela.

"Recibí los manuales, pero no leí" (Madre haitiana de $7^{\circ}$ básico).

Mencionan las actividades que se realizan en el colegio en donde no existe un espacio con jornadas interculturales para trabajar la diversidad.

"Acá no hacen nada para mostrar nuestra cultura, ni aquí en Los Ángeles ni en Santiago" (Madre venezolana de $5^{\circ}$ básico).

Las madres haitianas no se sienten integradas por parte de la sociedad chilena, es por esto que Barrios-Valenzuela \& Palou-Julián destacan elementos a tener en cuenta a la hora de valorar la integración por parte del país receptor:

El estado del capital humano, nivel de cualificación sociocultural que poseen los padres al llegar, la desigualdad en el ritmo de adquisición de la lengua por padres e hijos, las costumbres locales, los niveles locales de xenofobia con que se encontrarán, los medios de proveniencia de los inmigrantes. (2014, p. 410). 
De acuerdo a esto, es necesario tener en cuenta estos factores al momento de percibir la migración. Sin embargo, lo contrario sucede con las madres venezolanas que concuerdan en que sus hijos no han recibido tratos discriminatorios dentro de los establecimientos, han sido acogidos por los chilenos al igual que las familias en general y se sienten felices en la escuela.

"Hasta ahora nos han recibido de buena forma, ya tenemos amigos chilenos, en el edificio, acá en la escuela, en general ha sido una buena acogida" (Madre venezolana de $7^{\circ}$ básico).

"Mi hija está felíz" (Madre venezolana de $3^{\circ}$ básico).

"La relación con los apoderados es muy buena" (Madre venezolana de $5^{\circ}$ básico).

Se confirma la inclusión y acogida que han tenido los venezolanos por parte de los chilenos, tal y como ha sido documentado por la literatura nacional en Cano \& Soffia (2009) que comentan que la cara de los migrantes ha cambiado y llama la atención de los investigadores la forma en que éstos han ido insertándose social y culturalmente en la sociedad chilena. A pesar de ello, siendo el mismo idioma, existen palabras y expresiones que varían y por lo tanto acarrea burlas en algunas ocasiones. Son pequeños conflictos que se han solucionado de manera pacífica en tanto convivencia escolar y las madres y niños comprenden que son barreras del mismo idioma que a futuro se transforman en puentes entre culturas.

"De repente no entienden lo que decimos porque las palabras no están en su vocabulario" (Madre venezolana de $5^{\circ}$ básico).

Un factor importante al cruzar fronteras que mencionan la mayoría de las madres entrevistadas, es el clima, ya que Chile está ubicado al extremo sur del continente americano, por lo tanto, es un clima más extremo sobretodo en invierno y las nuevas migraciones provienen de un clima tropical, por ello, resulta compleja la adaptación.

"A mi hija le encanta venir a la escuela, lo único es que nos cuesta levantarnos por el frío, allá es otro clima" (Madre venezolana de $3^{\circ}$ básico).

Remarcan el hecho de no socializar los manuales de convivencia en alguna reunión y/o actividad en la escuela. 
"A mi me entregaron todos los manuales del colegio, pero no los leí, tampoco recibí información de ello acá" (Madre venezolana de $5^{\circ}$ básico).

Alrededor del 30 \% de las madres venezolanas entrevistadas observan que en su establecimiento existe preocupación por la diversidad cultural.

"Nos hacen traer comida típica, es entretenido porque para el día de su independencia, en septiembre, nos dan un lugar para mostrar lo típico de nuestro país y como somos hartos venezolanos en la escuela, es entretenido porque hemos hecho amigos" (Madre venezolana de $3^{\circ}$ básico).

Sin embargo, aproximadamente el $70 \%$ de las madres venezolanas explican que en los establecimientos no se realizan actividades para mostrar la diversidad cultural existente en los establecimientos, de esta manera, no sienten la confianza para integrarse plenamente en las actividades educativas.

"En el colegio no nos hacen mostrar nada de nuestra cultura, siento que nos hacen adaptarnos a la suya y en eso encuentro un poco egoísta la situación" (Madre venezolana de $1^{\circ}$ básico).

En el caso de las madres colombianas, se confirma el mismo patrón de discriminación que explican los haitianos, algunas expresan que por el color de piel sus hijos (as) reciben tratos vejatorios por parte de los compañeros de clase.

"A mi hija le decian negra, ella no es negra, ella es más morena, como algunos chilenos, pero no sé por qué la molestaban" (Madre venezolana de $1^{\circ}$ básico).

A pesar de ello, la mayoría de las madres coinciden en que sus hijos (as) han sido bien acogidos por los chilenos y que no han manifestado ningún problema de convivencia y maltrato en la escuela.

"Me gusta Chile porque nos han acogido muy bien, nada que decir de acá del establecimiento" (Madre colombiana de $5^{\circ}$ básico).

Se confirma el hecho de palabras y expresiones diferentes que existen dentro del mismo idioma, es por esto que ellas coinciden con las madres venezolanas explicando que han tenido algún conflicto en la escuela por esta razón. 
"Mi hijo un día le dijo 'señora' a la tía asistente, le dijo que así no se respondía, pero ella no entendió que asi decimos los colombianos, bueno, se conversó el tema con la encargada de convivencia y con la tía, pero él quedó muy mal después de la situación" (Madre colombiana de $5^{\circ}$ básico).

Gómez (2010) explica que la migración ha sido una actividad consustancial a la vida del hombre y le ha acompañado a lo largo de su historia. La conformación y estructuración de los pueblos ha obedecido en gran parte a migraciones voluntarias o forzadas; por lo tanto, habrá que mirar sus causas y efectos desprovistos de prejuicios y pretensiones. A pesar de poseer el mismo idioma, los conflictos van a surgir en discriminación en un amplio sentido, por falta de conocimiento o falta de comprensión, que en este caso, la posición es que la escuela debe apoyar incondicionalmente al alumnado y capacitar a sus profesionales para percibir y aceptar positivamente la diversidad cultural existente, es por esto como explica Jordan (1996), la influencia preponderante que tiene la personalidad del profesor, con sus valores y creencias en el cultivo y cambio de actitudes en torno a la diversidad cultural, es primordial.

Y de la misma manera se confirma la entrega de manuales por parte del establecimiento, la no revisión por parte de las familias y la no existencia de socialización de estos por parte de la escuela.

"Me entregan los manuales, pero no lo leí mucho, tampoco lo vemos durante el año" (Madre colombiana de $3^{\circ}$ básico).

De las 5 madres colombianas entrevistadas, 2 de ellas coinciden en que la escuela se preocupa por las actividades interculturales, sin embargo las otras 3 madres concuerdan en que la escuela no hace nada para integrarlos, simplemente impone la propia cultura y lo ve como proceso de adaptación de estas nuevas familias.

"A todos les han hablado de mis hijos, me invitaron a hacer algo de mi país, pero surgió otra situación y no se pudo hacer, pero existe la preocupación por nosotros, lo agradezco tanto, ya que mis hijos están felices" (Madre colombiana de $5^{\circ}$ básico).

"En la escuela no nos integran, nos gustaría mostrar más de nosotros, pero no podemos, tampoco lo hemos planteado al colegio" (Madres colombiana de $3^{\circ}$ básico). 
Se observó en general que aproximadamente el 30\% de los establecimientos intenta trabajar la diversidad cultural, aplicando elementos básicos para fomentar la buena convivencia e integración de las familias migradas, sin embargo, no se encuentra formalmente como plan de gestión de la convivencia, por lo tanto no se socializa a la comunidad educativa. El resto de los establecimientos, no lo trabaja y no lo presenta como plan en la gestión de la convivencia escolar. A diferencia de lo que plantea Camilleri (1985) en Jordan (1996) que explica que cuando la información acerca de la interculturalidad está bien planteada y bien trabajada, puede contribuir a reducir los estereotipos fáciles, así como generar mayores dosis de comprensión, tanto aptitudinal como actitudinal en toda la comunidad. Es por esto que es relevante evidenciar que los haitianos, en comparación a los venezolanos y colombianos, son discriminados no solamente en la escuela sino que también en la calle y esto se debe a los factores de adaptación, por parte de ellos y de integración por parte de los chilenos. En el caso del idioma, ha sido más difícil para los haitianos ya que ellos hablan el criollo haitiano o francés, la mayoría no posee una profesión debido a las malas condiciones de vida por parte del Estado y arrastran el peso de la inseguridad ciudadana y corrupción, similar a los colombianos. Sin embargo, el idioma castellano favorece a estos últimos. Lo contrario ocurre a los venezolanos que emigran de su país por razones políticas, siendo Venezuela un país diferente a los anteriores en la oferta del Estado para con sus ciudadanos, por lo tanto, la mayoría de los entrevistados posee una profesión y es por esto que han sabido integrarse fácilmente a la sociedad chilena y a la vez no han sufrido discriminación.

Sin embargo, se desconoce lo que desde hace tiempo atrás La Ley General de Educación 20.370 y la temática de Convivencia Escolar (2009) señalaron:

La educación se enmarca en el respeto y valoración de los seres humanos... de la diversidad multicultural... para convivir y compartir en forma responsable, tolerante, solidaria, democrática y activa en la comunidad escolar... (p. 1).

Esto explica que el sistema debe reconocer y valorar al individuo en su especificidad cultural y de origen, considerando su lengua, cosmovisión e historia, partiendo por las salas de clases, debiera ser considerado como un elemento relevante dentro de manuales y reglamentos. 
Tabla 2

Análisis cualitativo de contenido de planes de gestión de convivencia escolar.

\begin{tabular}{|c|c|c|c|}
\hline $\begin{array}{l}\text { Unidad de } \\
\text { análisis }\end{array}$ & $\begin{array}{l}\text { Códigos de } \\
\text { Análisis de } \\
\text { documento' }\end{array}$ & $\begin{array}{l}\text { Recurrencia entre } \\
\text { establecimientos } \\
(\text { ver tabla } 1)^{2}\end{array}$ & Categorías \\
\hline \multirow{3}{*}{$\begin{array}{l}\text { - Relaciones } \\
\text { entre los } \\
\text { miembros de } \\
\text { la comunidad } \\
\text { educativa. }\end{array}$} & \multirow[t]{3}{*}{ DIVCULT } & Se interpreta: $4,11,12,14,25$ & \multirow{3}{*}{$\begin{array}{l}\text { Involucramiento de la comunidad } \\
\text { educativa }\end{array}$} \\
\hline & & Se Concibe: $6,7,9,10,17,23$ & \\
\hline & & $\begin{array}{l}\text { Se omite: } 1,2,3,5,6,13,15,18, \\
19,20,21,22,23\end{array}$ & \\
\hline \multirow{3}{*}{$\begin{array}{l}\text { - Formación } \\
\text { social y } \\
\text { personal. }\end{array}$} & \multirow[t]{3}{*}{ JORINTER } & & \multirow[t]{3}{*}{$\begin{array}{l}\text { Espacios de Diálogo y de } \\
\text { participación }\end{array}$} \\
\hline & & Se concibe: 1 & \\
\hline & & $\begin{array}{l}\text { Se omite: todas las otras } \\
\text { escuelas }\end{array}$ & \\
\hline \multirow{3}{*}{$\begin{array}{l}\text { - Formación } \\
\text { que favorezca } \\
\text { la prevención } \\
\text { y un ambiente } \\
\text { armónico. }\end{array}$} & \multirow[t]{3}{*}{ RECMIN } & Se interpreta: - & \multirow{3}{*}{$\begin{array}{l}\text { Mejoramiento continuo } \\
\text { de la convivencia escolar } \\
\text { en el sistema educativo }\end{array}$} \\
\hline & & Se concibe: 2 & \\
\hline & & $\begin{array}{l}\text { Se omite: todas las } \\
\text { otras escuelas }\end{array}$ & \\
\hline \multirow{3}{*}{$\begin{array}{l}\text { - } \text { Respeto } \\
\text { mutuo }\end{array}$} & \multirow[t]{3}{*}{ TRABVAL } & Se interpreta: $5,10,25$ & \multirow{3}{*}{$\begin{array}{l}\text { Rescatar valores culturales e } \\
\text { internacionales atendiendo a la } \\
\text { comunidad educativa actual }\end{array}$} \\
\hline & & Se concibe: 2,7 & \\
\hline & & $\begin{array}{l}\text { Se omite: 1,3, 4, 6, 8, 9, 11, 12, } \\
13,14,15,16,17,18,19,20,21 \\
22,23,24\end{array}$ & \\
\hline \multirow{3}{*}{$\begin{array}{l}\text { - Formación } \\
\text { que favorezca } \\
\text { la prevención }\end{array}$} & \multirow[t]{3}{*}{ INNPROF } & Se interpreta: 1,5 & \multirow{3}{*}{$\begin{array}{l}\text { Capacitaciones, charlas } \\
\text { y/o jornadas de trabajo } \\
\text { que fomenten lo } \\
\text { establecido en el sistema } \\
\text { educativo para realizar } \\
\text { retroalimentación, } \\
\text { seguimiento y } \\
\text { actualización a través de } \\
\text { prácticas de trabajo. }\end{array}$} \\
\hline & & $\begin{array}{l}\text { Se concibe: } 3,7,9,13 \\
14,17,18,24\end{array}$ & \\
\hline & & $\begin{array}{l}\text { Se omite: } 2,4,6,8,10, \\
11,12,15,16,19,20,21 \\
22,23\end{array}$ & \\
\hline
\end{tabular}

1 De acuerdo a la codificación de términos se refiere: DIVCULT-diversidad cultural, JORINTERjornadas interculturales, RECMIN- recursos del Ministerio, TRABVAL-trabajo valórico, INNPROFinnovación del profesorado, PLACOG-plan de acogida, PRACULT- prácticas culturales, DISINTCULT-discursos interculturales.

2 "Se interpreta" se refiere a su trabajo explícito en las acciones del plan de gestión de convivencia escolar, mientras que "Se concibe" se trabaja sin estar especificado en el plan de gestión de convivencia escolar y finalmente "Se omite" entrega la información de no ser trabajado ni explicitado en el plan de gestión de convivencia escolar de acuerdo a la revisión de estos planes. 


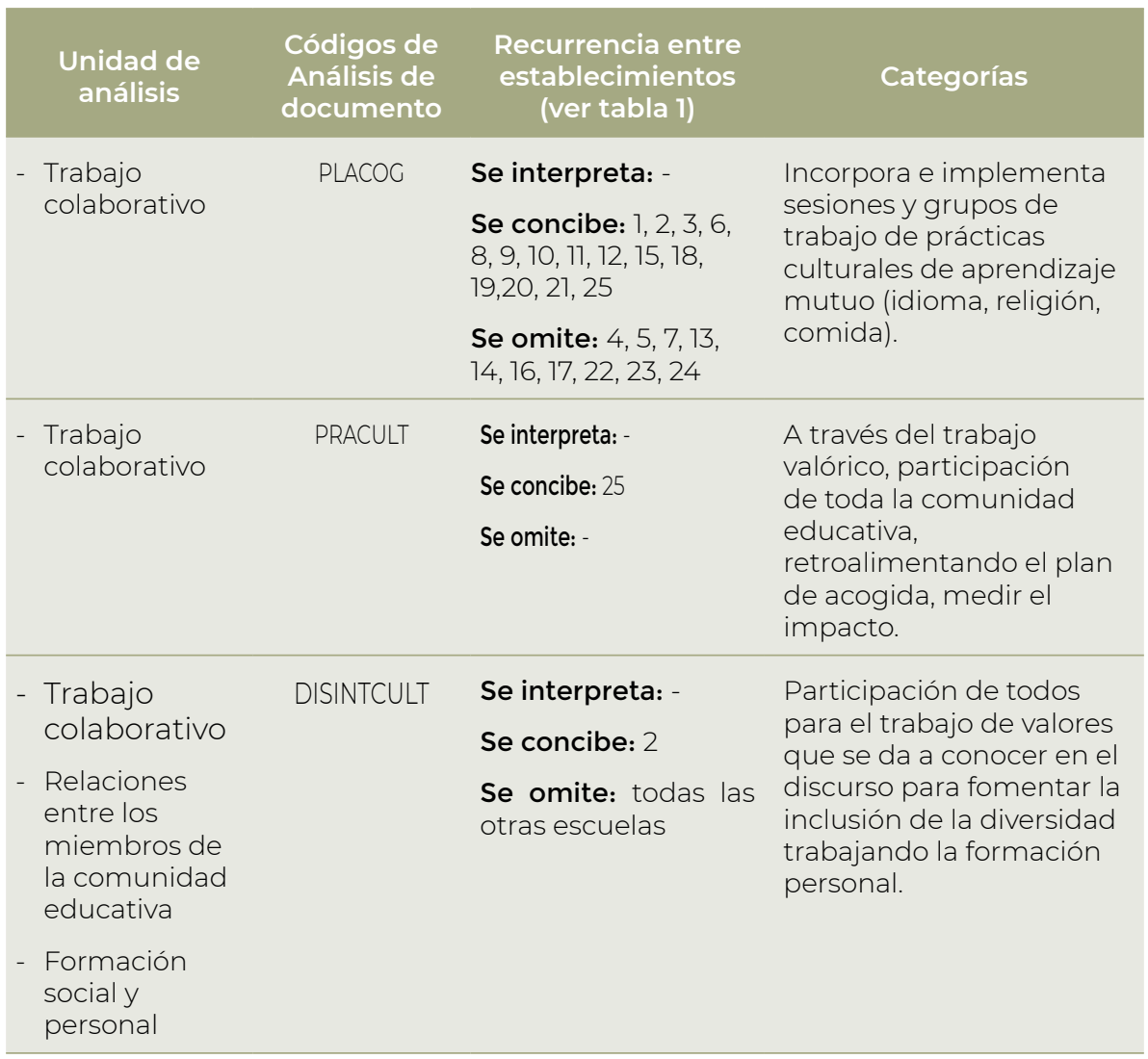

Fuente: elaboración propia de acuerdo a la revisión de planes de gestión de CE en 25 establecimientos y al análisis de contenido por Mayring (2000).

\section{Discusión}

Los resultados presentados ponen de manifiesto que no existe atingencia entre los manuales de gestión de la convivencia escolar y la interculturalidad existente, en donde los participantes en escuelas no trabajan la interculturalidad con la comunidad educativa, ya que tampoco lo tienen registrado como plan de acción de la convivencia escolar. Junto a ello, la comunidad escolar desconoce cómo incluirlo en los manuales para ser socializados entre los miembros de esta.

En primer término, respecto a la realidad de las familias migrantes en Chile, los discriminados son los grupos de extranjeros que acarrean problemas de pobreza e insatisfacción social desde su país de origen (que se hacen conocidos por los medios de comunicación) y que además provienen 
de una cultura, idioma y experiencias distintas y poseen un capital cultural y humano en desmedro. Sin embargo, aquellos que poseen un capital cultural y humano superior, que se expresan en el mismo idioma y que poseen características físicas similares, no son rechazados.

Segundo, Chile es considerado por la mayoría de latinoamericanos como un país de fácil acceso de ingreso, sin embargo, las políticas cambiaron desde que comenzaron los conflictos entre chilenos y extranjeros, aquellos que son considerados inferiores y que actualmente pertenecen a la mano de obra barata del país. Es por esto que (S. Piñera, comunicación personal, 9 de Abril de 2018) sugiere que se ha propuesto una Nueva Ley de Migración que abre las puertas a quienes ingresen a Chile en forma legal y vengan a aportar al desarrollo. Y cierra las puertas a los que pretenden ingresar ilegalmente, cometer delitos o causar daño. Por consiguiente, los haitianos deberán tramitar en el consulado chileno en su país una visa turista que durará 30 días, sin propósito de inmigración, residencia o desarrollo de actividades remuneradas. En cambio, explica Molina (2018) los venezolanos podrán tramitar una visa especial de "responsabilidad democrática" que se podrá extender hasta un año prorrogable a dos. Al momento de las entrevistas, muchas madres estaban en proceso de nacionalidad y otras ya la habían obtenido. Por ello, sus hijos e hijas serán parte de la comunidad educativa. Por este motivo, sería recomendable utilizar algunas estrategias para el trabajo de la interculturalidad en los colegios, concienciando principalmente a los docentes que son los transmisores principales de valores desde la infancia.

\section{Conclusión}

En este trabajo se ha pretendido revelar y reflexionar sobre la realidad de la convivencia escolar intercultural en los colegios, poniendo de manifiesto el trabajo de ello, por lo tanto, al no considerarse la interculturalidad como plan de convivencia dentro del establecimiento en el proceso formador y formal de clases, se espera que los estudiantes sientan muy poca empatía y crezcan en una sociedad discriminadora. Es importante conocer esta etapa clave en su desarrollo, ya que como explica el Colegio Oficial de Psicólogos de Madrid (2016) se debe tener muy presente la edad de los niños en relación a sus reacciones. En niños de entre $\mathrm{O}$ a 12 años, que tienen más dificultad para describir lo que sienten, es habitual que, ante una situación de crisis, se sientan indefensos, inseguros y aparezcan conductas regresivas. Es por esto que en los establecimientos se necesita una mirada profunda de lo que es Chile actualmente en consideración a la interculturalidad, de aprendizaje de valores 
y adaptación ya que la escuela forma, informa y practica valores de convivencia, en donde la comunidad educativa experimenta procesos y aprende a vivir en sociedad.

\section{REFERENCIAS BIBLIOGRÁFICAS}

Aguilar, M. J. (2012). Pensar la intervención social con personas migradas: un desafío a nuevas formas de intervención desde el trabajo social. En A. Avaria (Ed.), Desafíos de la migración. ¿Cómo acercarnos a las personas migradas? Miradas de y desde la investigación e intervención social (primera ed., Vol, 1 pp. 79-113). Santiago, Chile: Universidad Santo Tomás.

Avaria, A. (Ed.). (2012). Desafíos de la migración. ¿Cómo acercarnos a las personas migradas? Miradas de y desde la investigación e intervención social. Santiago, Chile: Universidad Santo Tomás.

Barrios-Valenzuela, L., \& Palou-Julian, B. (2014). Educación Intercultural en Chile: la integración del alumnado extranjero en el sistema escolar. Educación y Educadores, 77 (3), 405-426. Recuperado de https:// www.redalyc.org/pdf/834/83433781001.pdf

Bardin, L. (1996). Análisis de contenido. España: Akal Ediciones.

Cáceres, P. (2003). Análisis cualitativo de contenido: una alternativa metodológica alcanzable. Psicoperspectivas revista de la escuela de psicología facultad de filosofía y educación pontificia universidad católica de Valparaíso, Vol. II. 53 - 82. Recuperado de http://10.5027/psicoperspectivas-vol2-issuel-fulltext-3

Camilleri, C. (1985). Antropología cultural y educación. Francia: Unesco.

Cano, V., \& Soffia, M. (2009). Los estudios sobre migración internacional en Chile: apuntes y comentarios para una agenda de investigación actualizada. Papeles de Población, 15(61), 129-167.

Cano, V., \& Ávalos, B. (2012). Estrategias de intervención social con personas migradas. Un desafío en constante reflexión en A. Avaria (Ed.), Desafíos de la migración. ¿Cómo acercarnos a las personas migradas? Miradas de y desde la investigación e intervención social (primera ed., Vol, 1 pp. 113-133). Santiago, Chile: Universidad Santo Tomás. 
Colegio Oficial de Psicólogos de Madrid. (2016). Guía para la intervención psicológica con inmigrantes y refugiados. Colegio Oficial de Psicólogos de Madrid. Recuperado de https://www.ucm.es/data/cont/docs/3152016-06-02-g.refugiados_PDF.pdf

Cornejo, H. (2007). Modelo comprensivo-interpretativo del proceso de apropiación subjetiva de tecnologías en organizaciones. Revista Iberoamericana Educación, Salud, Trabajo, 5(4), 9.

Cruz, E. (2015). La interculturalidad en las políticas de educación intercultural. Praxis \& Saber, 6(12), 191-207.

Fernández, F. (2002). El análisis de contenido como ayuda metodológica para la investigación. Revista Ciencias Sociales, 96, 35-53.

García, N. (2004). Diferentes, desiguales y desconectados, Mapas de la Interculturalidad. Barcelona, España: Gedisa.

Garreta, J. (2000). Els musulmans a Catalunya. España: Pagès Editors.

Gómez, J. (2010). La migración internacional: teorías y enfoques, una mirada actual. Semestre Económico, 13(26), 81-99. Recuperado de https:// www.redalyc.org/pdf/1650/165014341004.pdf

Guardián-Fernández, A. (2007). El paradigma Cualitativo en la investigación Socio-Educativa. San José, Costa Rica: PrintCenter.

Jansen, E. (2004). The influence of the curriculum organization on study progress in higher education. Higher Education, 47, 411435. Recuperado de https://link.springer.com/article/10.1023/ B:HIGH.0000020868.39084.21

Jordan, J. (1996). La Interculturalidad en la escuela. Revista interuniversitaria de formación del profesorado, 25, 71-84. Recuperado de https://dialnet.unirioja.es/servlet/articulo?codigo $=117894$

Ley $N^{\circ}$ 20.370. Diario Oficial de la República de Chile, Santiago, Chile, 12 de septiembre de 2009. Recuperado de https://www.leychile.cl/ Navegar?idNorma=1006043

Mato, D. (2009). Instituciones interculturales de educación superior en América Latina: procesos de construcción, logros, innovaciones y desafíos. Caracas, Venezuela: IESALC-Unesco. 
Mayring, P. (2000) Qualitative content analysis. Forum qualitative social research, 7(2). DOI: http://dx.doi.org/10.17169/fqs-1.2.1089

Ministerio de Desarrollo Social (2015). CASEN 2015: Encuesta de caracterización socioeconómica nacional. Santiago, Chile: MIDEPLAN.

Ministerio de Desarrollo Social (2017). CASEN 2017: Encuesta de caracterización socioeconómica nacional. Santiago, Chile: MIDEPLAN.

Molina, P. (11 de abril de 2018). Por qué Chile facilita la llegada de inmigrantes de Venezuela y pone dificultades a los de Haití. BBC Mundo online.

Ministerio de Educación (2015). Política Nacional de Convivencia Escolar 2015-2018. Ministerio de Educación. Santiago, Chile. Recuperado de http://convivenciaescolar.mineduc.cl/wp-content/uploads/2018/10/ Politica-Nacional-de-Convivencia-Escolar-2015.2018.pdf

Ministerio de Educación de Chile (MINEDUC) (2018). Política Nacional de Estudiantes Extranjeros 2018-2022. Ministerio de Educación. Santiago, Chile. Recuperado de https://www.mineduc.cl/wp-content/uploads/ sites/19/2018/05/PoliticaNacionalMigrantes.pdf

Nail, O., Valdivia, J., Gajardo, J., Viejo, C., Salas, R., \& Romero, G. (2018). Estudio de casos: tensiones y desafíos en la elaboración de la normativa escolar en Chile. Educ. Pesqui, 44, 1-22. DOI: https://doi.org/10.1590/s16784634201711167834

Novaro, G. (Coord.). (2011). La interculturalidad en debate. Experiencias formativas y procesos de identificación en niños indígenas y migrantes. Buenos Aires, Argentina: Biblos.

Puente, E. (2005). El estado y la interculturalidad en el Ecuador. Iconos, Revista de Ciencias Sociales, 27, 172-173.

Ramírez, S., \& Justicia, F. (2006). El maltrato entre escolares y otras conductas problema para la convivencia. Revista Electrónica de Investigación Psicoeducativa, 9(4), 265-290. Recuperado de https://www.redalyc. org/pdf/2931/293122821007.pdf

Stefoni, C., Stang, F., \& Riedemann, A. (2016). Educación e interculturalidad en Chile: Un marco para el análisis. Estudios internacionales (Santiago), 48(185), 153-182. Recuperado de https://scielo.conicyt.cl/pdf/rei/ v48n185/art08.pdf 
UNESCO (2008). Educación y diversidad cultural. Lecciones desde la práctica innovadora en América Latina. Santiago, Chile: Unesco.

UNESCO (2013). El Informe Situación Educativa de América Latina y el Caribe: Hacia la educación de calidad para todos al 2015. Recuperado de http://www.unesco.org/new/fileadmin/ MULTIMEDIA/FIELD/Santiago/images/SITIEDespanol.pdf

Valles, M. (2000). Técnicas Cualitativas de Investigación Social Reflexión metodológica y Práctica Profesional. Madrid, España: Síntesis, S.A.

Valverde, Adrián. (2010). La formación docente para una educación intercultural en la escuela secundaria. Cuicuilco, 17(48), 133-147. Recuperado de http://www.scielo.org.mx/scielo.php?script=sci_arttext\&pid=S0185$16592010000100008 \&$ lng=es\&tlng=es 